\title{
Diagnostic findings caused by cutting of the iliotibial tract and anterolateral ligament in an ACL intact knee using a standardized and automated clinical knee examination
}

\author{
Timothy Lording ${ }^{1} \cdot$ Shaun K. Stinton ${ }^{2} \cdot$ Philippe Neyret $^{3} \cdot$ Thomas P. Branch $^{4}$
}

Received: 8 November 2016 / Accepted: 27 February 2017 / Published online: 17 March 2017

(C) The Author(s) 2017. This article is published with open access at Springerlink.com

\begin{abstract}
Purpose The purpose of this study was to evaluate the separate contribution of the two definitions of the anterolateral ligament (ALL), the mid-third lateral capsular ligament (MTLCL) and deep capsule-osseous layer of the iliotibial tract (dcITT) in addition to the superficial iliotibial tract (sITT) to the control of tibial motion with respect to the femur during the application of force/torque seen during the three tests of the standard clinical knee examination (AP Lachman test, tibial axial rotation test and varus-valgus stress test).

Methods Six pelvis-to-toe cadaveric specimens were examined using an automated testing device that carried out the three components of the clinical knee examination. Internal/external rotation torque, anteroposterior load and adduction/abduction torque were applied, while torque/ force and positional measurements were recorded. Sequential sectioning of the structures followed the same order for each knee, sITT, dcITT and MTLCL. Testing was repeated after release of each structure.

Results During the tibial axial rotation test, releasing the sITT caused an increase in internal rotation of $2.6^{\circ}(1.4$ $\left.4.1^{\circ}, p<0.0005\right)$, while release of the dcITT increased internal rotation an additional $0.8^{\circ}\left(0.4-1.1^{\circ}, p<0.0015\right)$. Changes in secondary motions of the tibia after sITT
\end{abstract}

Shaun K. Stinton

stinton@gmail.com; s.stinton@getmotion.com

1 Melbourne Orthopaedic Group, Melbourne, VIC, Australia

2 ArthroMetrix LLC, 441 Armour Place NE, Atlanta, GA 30324, USA

3 Department Orthopedic Surgery, Centre Albert-Trillat, Hôpital de la Croix-Rousse, Lyon, France

4 University Orthopedics, Decatur, GA, USA release demonstrated an increase in anterior translation of $1.2 \mathrm{~mm}(0.6-2.0 \mathrm{~mm}, p<0.0005)$ during internal rotation, while release of the dcITT increased the same motion an additional $0.4 \mathrm{~mm}(0.2-0.5 \mathrm{~mm}, p<0.0005)$. During the AP Lachman test, release of the sITT caused the tibia to move more anteriorly by $0.7 \mathrm{~mm}(0.4-1.1 \mathrm{~mm}, p<0.0005)$ and increased internal rotation by $2.7^{\circ}\left(0.9-5.2^{\circ}, p<0.004\right)$. The additional release of the dcITT resulted in more anterior translation by $0.3 \mathrm{~mm}(0.1-0.4 \mathrm{~mm}, p<0.002)$ and internal rotation by $0.9^{\circ}\left(0.2-1.7^{\circ}, p<0.005\right)$. During the varus-valgus stress test, release of the sITT permitted $0.9^{\circ}$ $\left(0.4-1.4^{\circ}, p<0.0005\right)$ more adduction of the tibia, while the additional release of the dcITT significantly increased adduction by $0.4^{\circ}\left(0.2^{\circ}-0.5^{\circ}, p<0.001\right)$. Release of the MTLCL had a nominal but significant increase in internal rotation, $0.6^{\circ}\left(0.1-1.1^{\circ}, p<0.0068\right)$ and external rotation, $-0.1^{\circ}\left(-0.1^{\circ}\right.$ to $\left.-0.2^{\circ}, p<0.0025\right)$ during the tibial axial rotation test, anterior translation of $0.2 \mathrm{~mm}(0.0-0.4 \mathrm{~mm}$, $p<0.021$ ) only during the AP Lachman test, and adduction rotation, $0.2^{\circ}\left(0.0-0.3^{\circ}, p<0.034\right)$ only during the varusvalgus stress test.

Conclusion The presence of increased adduction during an automated knee examination provides unique information identifying the release of the sITT, dcITT and the MTLCL in this cadaveric study. While their sequential release caused similar pattern changes in the three components of the automated knee examination, the extent of change due to release of the MTLCL was markedly less than after release of the dcITT which was markedly less than after release of the sITT.

Keywords Knee ligaments $\cdot$ Knee laxity $\cdot$ Ligament biomechanics $\cdot$ Anterolateral ligament 


\section{Introduction}

The key to the successful treatment of knee ligament injuries is a correct diagnosis. Without a proper diagnosis, ligament injuries are either missed or unnecessary surgery is performed. Ligament injuries result in biomechanical changes within the knee, which can be identified by changes in laxity during the three tests comprising the standard clinical knee examination (AP Lachman test, varus-valgus stress test \& tibial axial rotation test). While the clinical knee examination profile is well understood for the major knee ligaments [e.g. Anterior cruciate ligament (ACL), posterior cruciate ligament (PCL), medial and lateral collateral ligaments (MCL, LCL)], profiles for secondary ligamentous structures are not as well understood.

The anterolateral ligament (ALL) has been recently popularized in the literature [2, 6-8, 12, 13, 16-19, 22-24]. Dodds et al. suggest that it is below the deep capsulosseous layer (dcITT) of the iliotibial tract (ITT) but superficial to the capsule [8], while Claes et al. reported that it is a part of the capsular complex [7]. Kittl et al. chose to consider the dcITT and the underlying anterolateral capsule separately [15], while others considered it all-in-one as the anterolateral capsule (ALC) [11]. For this study, two components of the ITT were examined separately: the superficial ITT (sITT) and the deep capsulosseous layer of the ITT (dcITT). In addition, the medial third lateral capsular ligament (MTLCL) was examined separately as another definition of the ALL below the dcITT and as a part of the anterior capsular complex. Discussions of the biomechanical function of these 'ligaments' along with the superficial ITT (sITT) have focused on their role in the control of tibial axial rotation and/or anterior translation while limiting review of the other directions of increased "joint play" $[6-8,14,22]$. Furthermore, no cadaveric biomechanical study has been performed looking at the impact of release of the sITT, dcITT and/or MTLCL in the context of the standard clinical knee examination. The goal of this study was to provide information to aid the surgeon in making the appropriate diagnosis of a sITT, dcITT and/or MTLCL (collectively the anterolateral corner) injury in the ACL intact knee. For this study, it was postulated that if injury to the sITT, dcITT and/or MTLCL could not be identified in the ACL intact knee then the importance of these ligaments would be diminished in the face of an anatomic ACL reconstruction.

The purpose of this study was to use an automated knee examination to evaluate how SITT, dcITT and MTLCL integrity impacts knee biomechanics in the ACL intact knee. The hypothesis was that release of the sITT, dcITT and/or MTLCL would result in significant and identifiable changes in the extent and pattern of motion during an automated knee examination that mimics the three components of a clinical knee examination (AP Lachman test, tibial axial rotation test and the varus-valgus stress test).

\section{Materials and methods}

A cadaveric study was undertaken using a previously described automated system $[3-5,20,21]$ that mimics the three components of the clinical knee examination (AP Lachman test, tibial axial rotation test and the varus-valgus stress test). The study consisted of sequential release of the SITT, dcITT and MTLCL followed by evaluation of each knee with the three components of the automated knee examination (Table 1). No IRB approval was required for cadaveric studies at the institution where testing was performed.

Six fresh frozen, pelvis to toe cadaveric specimens (12 knees) were used for the study. Specimens with a body mass index (BMI) over $28 \mathrm{~kg} / \mathrm{m}^{2}$, with a history of lower limb trauma, previous knee surgery or medical conditions that may have impacted the health of the knee, or aged over 75 years were excluded. Potential specimens were screened with radiographs and magnetic resonance imaging (MRI), and specimens with evidence of arthritis, meniscal or ligament damage were also excluded. The mean specimen age was 55 years (35-71 years).

A standardized, automated and reproducible (STAR) knee examination system consisting of six servomotors combined with six torque sensors was used to perform single-axis tests in three planes: (1) external-internal rotation; (2) anterior-posterior; and (3) varus-valgus rotation. For rotational testing, the limb was rotated by a footplate about an approximate centre of tibial rotation $2.5 \mathrm{~cm}$ anterior to
Table 1 This table outlines the sequence of cutting conditions for this study

\begin{tabular}{lllllll}
\hline Test & ACL & ALL/capsule & sITB & dITB & sITB patella & \#Knees \\
\hline 1 & $\mathrm{U}$ & $\mathrm{U}$ & $\mathrm{U}$ & $\mathrm{U}$ & $\mathrm{U}$ & 12 \\
2 & $\mathrm{U}$ & $\mathrm{U}$ & $\mathrm{U}$ & $\mathrm{U}$ & $\mathrm{C}$ & 12 \\
3 & $\mathrm{U}$ & $\mathrm{U}$ & $\mathrm{C}$ & $\mathrm{U}$ & $\mathrm{C}$ & 12 \\
4 & $\mathrm{U}$ & $\mathrm{U}$ & $\mathrm{C}$ & $\mathrm{C}$ & $\mathrm{C}$ & 12 \\
5 & $\mathrm{U}$ & $\mathrm{C}$ & $\mathrm{C}$ & $\mathrm{C}$ & $\mathrm{C}$ & 6 \\
\hline
\end{tabular}

$U$ uncut, $C$ cut 
the heel. Rotation occurred in one direction until a maximum torque of $5 \mathrm{~N} \mathrm{~m}$ was reached, at which point the servomotor changed direction. One rotational cycle was considered to be from $0 \mathrm{~N} \mathrm{~m}$ torque to full external rotation, to full internal rotation, and back to $0 \mathrm{~N}$ m torque. For each test, one pre-conditioning cycle and three data acquisition cycles were performed. A similar method was used for anteroposterior translation and varus-valgus testing. For anteroposterior translation, a lever arm was positioned under the calf just distal to the tibial tuberosity with a strap around the leg, and a peak force of $200 \mathrm{~N}$ was used. For varus-valgus testing, rotation occurred at the footplate, to a peak torque of $14 \mathrm{~N} \mathrm{~m}$. These loads were chosen based upon previous in-vivo biomechanical studies with the desire to fully characterize the toe region of load-deformation curves seen in the knee [4].

Positional data were recorded using an electromagnetic motion analysis system (trakSTAR, Ascension Technology Corporation, Shelburne, VT). Sensors were mounted directly to the femur and tibia with screw fixation. Positional data from the electromagnetic system and torque data from the torque sensors were continuously recorded during testing. The motion data was accurate to within $0.48 \mathrm{~mm}$ and $0.3^{\circ}\left(0.88 \mathrm{~mm}\right.$ and $0.48^{\circ}-95 \%$ confidence interval) based on root mean square error as reported by the manufacturer.

Each specimen was stored in a sealed polyethylene bag at $-20^{\circ} \mathrm{C}$ and thawed at room temperature for at least $24 \mathrm{~h}$ prior to testing. The specimen was positioned supine in the automated testing device (Fig. 1) such that the knee joint line was approximately $1 \mathrm{~cm}$ distal to the femoral pad. The knees were flexed to $30^{\circ}$ and the pelvis was clamped to the examination table. Two incisions were made on both the lateral and medial aspects of the thigh, at approximately the junction of the middle and distal third of the femur. Two metal plates, $3 \mathrm{~cm}$ wide, were inserted to clamp the femur. The anterior plate was flat, while the posterior plate was grooved to accommodate the linea aspera. The plates were passed through the fascia lata well anterior and posterior to the borders of the ITT to allow it free movement, and screwed together to control movement of the femur. A diagonal set screw in the anterior plate ensured rotational control. The coronal and rotational position of the limbs was adjusted until the patella faced anteriorly and the feet were then strapped to the footplates. A $3 \mathrm{~cm}$ incision was made over the anteromedial surface of each tibia, just medial and distal to the tibial tuberosity. A mount for the electromagnetic tracking sensor was affixed to the tibia using two brass screws to avoid interference. Care was taken to avoid damaging the tendons at the pes anserinus. The femoral sensors were mounted in a similar fashion to the anterolateral femur just distal to the femoral clamps. Each knee was initially held with a patella clamp applied with $133 \mathrm{~N}$ force, after which the femoral stabilizing plates were secured to a board to minimize femoral movement during testing. The electromagnetic tracking system was then calibrated and the patella clamps were removed.

A baseline test cycle (Test 1) was performed, and repeated after removal of the skin and subcutaneous tissues from the level of the thigh clamps to approximately $10 \mathrm{~cm}$ distal to the knee (Test 2). The sequential cutting phase of the experiment was then carried out. The sITT was dissected from the lateral aspect of the patella and released at Gerdy's tubercle, taking care not to damage the deeper structures, and a test cycle performed (Test 3). With the sITT detached, the dcITT was identified and released distally from the tibia. A test cycle was performed with both the sITT and dcITT released (Test 4). Finally, release of the meniscotibial ligament was completed from medial to the lateral collateral ligament to the anterior horn of the lateral meniscus securing a complete release of the MTLCL. After release of the capsular ligaments, Test 5 was performed with the sITT, dcITT and MTLCL all cut. Only 6 of the 12 knees were available for statistical comparison in this group.

Throughout each dissection, digital photographs and notes were taken to document the specific anatomic findings for that specimen. Anatomical measurements were not taken.
Fig. 1 a Cadaver setup b placement of electromagnetic sensors
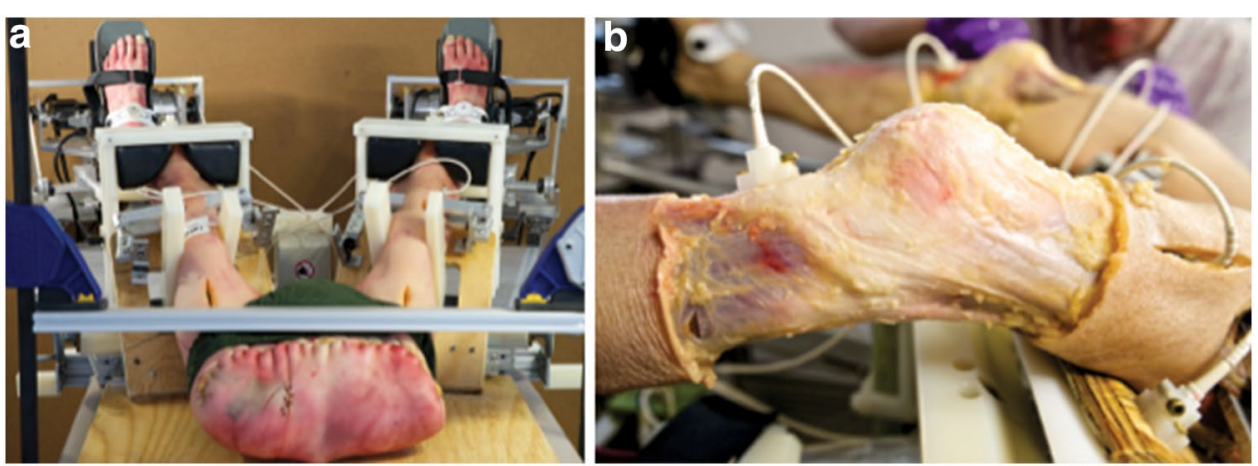


\section{Statistical analysis}

Matlab (MathWorks, Inc., Natick, MA) and R (R: A language and environment for statistical computing. R Foundation for Statistical Computing, Vienna, Austria. URL http://www.R-project.org/) were used for data analysis. Using the positional data from the electromagnetic sensors, a kinematic path in all three dimensions was established for the tibia with respect to the femur. Combining this three dimensional kinematic data with the load data from the torque sensors, a load-deformation curve was constructed for each test cycle, with rotation/translation on the $x$-axis and torque/force on the $y$-axis. For the purpose of this study, the load-deformation curve was restricted to tracking the major direction of load application. The load-deformation curve was interpolated for a set of 500 points between -5 and $5 \mathrm{~N}$ m for external and internal rotation, -200 and $200 \mathrm{~N}$ for anterior and posterior translation, or -14 and $14 \mathrm{~N} \mathrm{~m}$ for valgus-varus rotation respectively. Mean curves were then constructed using the average rotation/translation for each of the 500 standardized $y$-value points from the load-deformation curves across all specimens. The slope of the curve represents rotational stiffness, with a steeper curve representing a stiffer or less compliant knee. Pointwise Wilcoxon signed rank testing (non-parametric) was applied across the 500 points. A pre-study power analysis was performed to determine the number of specimens required to detect a difference between groups equal to the accuracy of the measurement system $\left(0.3^{\circ}\right)$. Due to the small standard deviation associated with the automated testing system when testing cadaveric specimens in previous studies, a large number of specimens was not required. A sample size of 12 knees provided a power of 0.97 and a sample size of 6 knees provided a power of 0.80 .

\section{Results}

In this study, removal of the skin and subcutaneous tissue had no significant impact on knee kinematics during the automated knee examination. Sectioning of the ligament between the lateral patella and the sITT did have a small but significant impact during each examination. These changes in knee kinematics during each of the automated knee examinations are seen in Tables 2 through 4 . The mean difference or mean change due to sectioning of each ligament is shown along with the confidence intervals. The total change in motion between the tibia and the femur during each of the examinations is also included.

The results for the tibial axial rotation test after sequential cutting of the sITT at the patella, sITT and dcITT are presented in Fig. 2. Load-deformation curves representing motions resulting from the application of an external/ internal rotational torque during the test are presented. Changes in extent are visualized by curve displacement and changes in stiffness are visualized by slope differences. All mean changes between curves at the endpoints are listed in Table 2 for the primary direction and most significant

Table 2 The change in tibial axial rotation during the tibial axial rotation test between each condition and its level of statistical significance

Tibial axial rotation test (external/internal rotation)

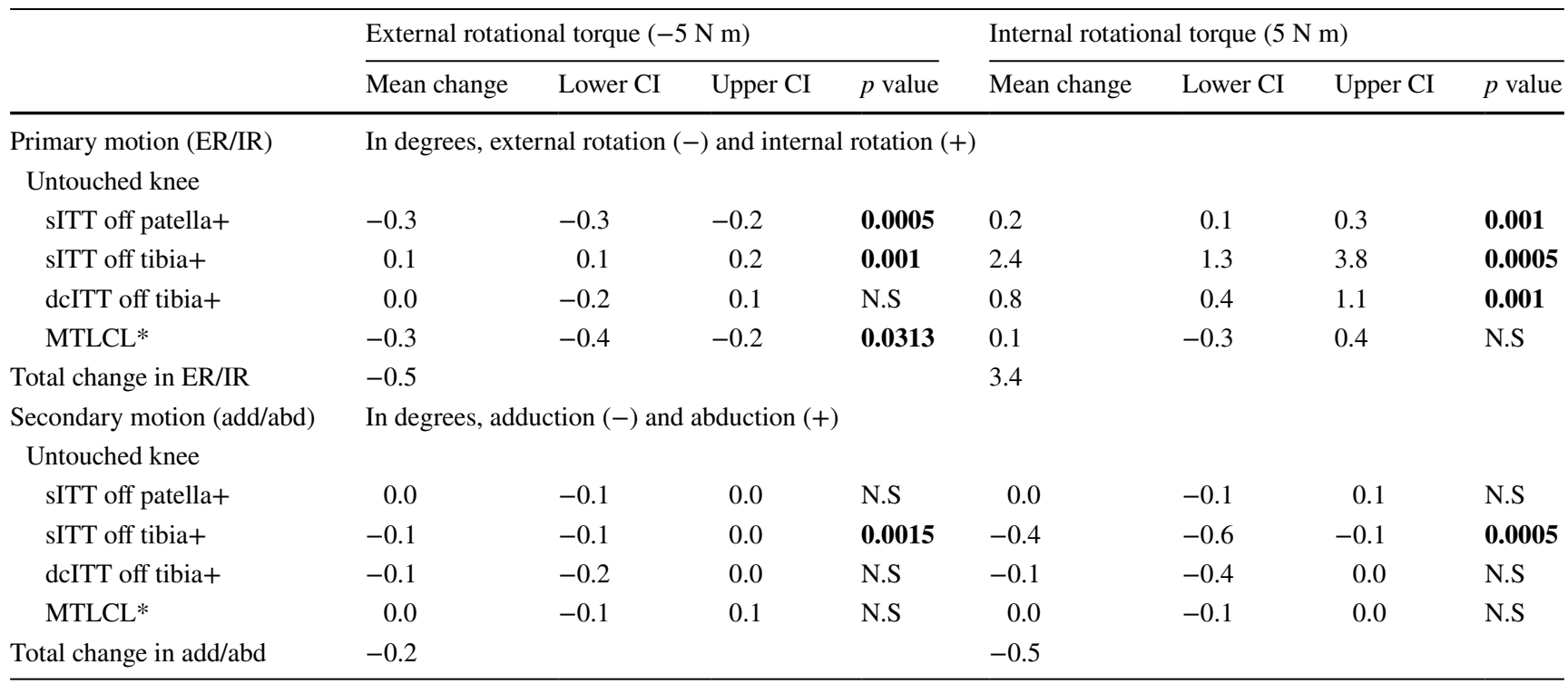

Significant $p$ values $<0.05$ are in bold

+12 knees; *6 knees 
secondary direction during the torque application for the tibial axial rotation test. The majority of change occurred after sectioning of the sITT resulting in increased internal rotation and adduction during the application of internal rotation torque. While the dcITT mimicked the sITT, motion was to a lesser extent. The MTLCL had a nominal effect only during external rotation torque.

The results for the AP Lachman test after sequential cutting of the sITT at the patella, sITT and dcITT are presented in Fig. 3. All mean changes between curves at the endpoints are listed in Table 3 for the primary direction and most significant secondary direction during the torque application for the AP Lachman Test. The majority of change occurs after release of the sITT resulting in increased anterior translation and internal rotation during the application of an anterior load. While the dcITT mimicked the sITT, the motion was to a lesser extent. The MTLCL had no significant effect on primary or secondary motions of the tibia with respect to the femur during application of an anterior/posterior load during the automated knee examination.

During the varus-valgus stress test, sequential cutting of the sITT at the patella, sITT and the dcITT caused significant changes to occur (Fig. 4). All mean changes between curves at the endpoints are listed in Table 4 for the primary direction and most significant secondary direction during the torque application for the varus-valgus stress test. The majority of change occurs after sectioning of the sITT resulting in increased adduction rotaton and internal rotation during the application of an adduction torque. While the dcITT mimicked the sITT, the motion was to a lesser extent. The MTLCL had a nominal effect during the application of abduction torque only resulting in a slight increase in external rotation.

In all cadavers, the sITT was found to have an insertion into Gerdy's tubercle creating a passive structural restraint across the tibiofemoral joint. The structural characteristics of this passive restraint were always found to be robust in nature. The dcITT was identified in all specimens. In some cases, it was a robust and easily identifiable structure, while in others it was flimsy and almost translucent. As noted, there was variation in both the apparent length of this structure and in its insertion point on the tibia, although formal anatomical measurements were not made (see Fig. 1b). Release of the anterolateral meniscotibial ligament effectively released the MTLCL (see Fig. 1c).

\section{Discussion}

The most important finding in this study was that an automated knee examination could identify the sequential release of the sITT and dcITT in the ACL intact knee. This identification could be achieved through the increases in anterior translation and internal rotation during the AP Lachman test, increases in internal rotation and anterior translation during the tibial axial rotation test, and, most importantly, through increases in adduction, internal

Table 3 This table identifies the change in anterior/posterior translation during the AP Lachman test between each condition and its level of statistical significance

\begin{tabular}{|c|c|c|c|c|c|c|c|c|}
\hline \multicolumn{9}{|c|}{ AP Lachman test (AP Translation) } \\
\hline & \multicolumn{4}{|c|}{ Posterior load $(-200 \mathrm{~N})$} & \multicolumn{4}{|c|}{ Anterior load $(200 \mathrm{~N})$} \\
\hline & Mean change & Lower CI & Upper CI & $p$ value & Mean change & Lower CI & Upper CI & $p$ value \\
\hline Primary motion (post/ant) & \multicolumn{8}{|c|}{ In $\mathrm{mm}$, posterior translation $(-)$ and anterior translation $(+)$} \\
\hline \multicolumn{9}{|l|}{ Untouched knee } \\
\hline sITT off patella+ & -0.1 & -0.1 & 0 & N.S & 0.1 & 0.0 & 0.2 & 0.0425 \\
\hline sITT off tibia+ & 0.2 & 0.1 & 0.4 & 0.0093 & 0.6 & 0.3 & 1.0 & 0.0005 \\
\hline dcITT off tibia+ & 0.1 & -0.1 & 0.2 & N.S & 0.3 & 0.1 & 0.4 & 0.0015 \\
\hline MTLCL* & 0.0 & -0.2 & 0.2 & N.S & 0.1 & -0.2 & 0.4 & N.S \\
\hline Total change in AP & 0.3 & & & & 1.1 & & & \\
\hline Secondary motion (ER/IR) & \multicolumn{8}{|c|}{ In $\mathrm{mm}$, posterior translation $(-)$ and anterior translation $(+)$} \\
\hline \multicolumn{9}{|l|}{ Untouched Knee } \\
\hline sITT off patella+ & -0.2 & -0.4 & 0.1 & N.S & 0.6 & 0.1 & 1.1 & 0.021 \\
\hline sITT off tibia+ & 0.5 & -0.2 & 1.3 & N.S & 2.1 & 0.7 & 4.0 & 0.0034 \\
\hline dcITT off tibia+ & -0.2 & -0.9 & 0.4 & N.S & 0.8 & 0.2 & 1.7 & 0.0049 \\
\hline MTLCL* & 0.1 & -0.7 & 1.2 & N.S & -0.1 & -1.0 & 0.7 & N.S \\
\hline Total change in ER/IR & 0.2 & & & & 3.5 & & & \\
\hline
\end{tabular}

Significant $p$ values $<0.05$ are in bold

+12 knees; *6 knees 
Table 4 This table identifies the change in adduction/abduction rotation during the varus-valgus stress test between each condition and its level of statistical significance

Varus-valgus stress test (adduction/abduction rotation)

\begin{tabular}{|c|c|c|c|c|c|c|c|c|}
\hline & \multicolumn{4}{|c|}{ Adduction rotation torque $(-14 \mathrm{~N} \mathrm{~m})$} & \multicolumn{4}{|c|}{ Abduction rotation torque $(14 \mathrm{~N} \mathrm{~m})$} \\
\hline & Mean change & Lower CI & Upper CI & $p$ value & Mean change & Lower CI & Upper CI & $p$ value \\
\hline Primary motion (add/abd) & \multicolumn{8}{|c|}{ In degrees, adduction $(-)$ and abduction $(+)$} \\
\hline \multicolumn{9}{|l|}{ Untouched knee } \\
\hline sITT off patella+ & -0.1 & -0.1 & 0.0 & 0.0234 & 0.0 & 0.0 & 0.0 & N.S \\
\hline sITT off tibia+ & -0.8 & -1.3 & -0.4 & 0.0005 & -0.1 & -0.2 & 0.0 & N.S \\
\hline dcITT off tibia+ & -0.3 & -0.5 & -0.2 & 0.0010 & 0.0 & -0.1 & 0.1 & N.S \\
\hline MTLCL* & -0.1 & -0.2 & 0.0 & N.S & 0.0 & -0.1 & 0.1 & N.S \\
\hline Total change in ER/IR & -1.3 & & & & -0.1 & & & \\
\hline Secondary motion (ER/IR) & \multicolumn{8}{|c|}{ In degrees, external rotation $(-)$ and internal rotation $(+)$} \\
\hline \multicolumn{9}{|l|}{ Untouched knee } \\
\hline sITT off patella+ & 0.1 & -0.2 & 0.2 & N.S & 0.1 & -0.1 & 0.3 & N.S \\
\hline sITT off tibia+ & 2.5 & 1.1 & 4.3 & 0.0005 & 0.8 & 0.4 & 1.2 & 0.0005 \\
\hline dcITT off tibia+ & 0.4 & 0.2 & 0.8 & 0.0049 & 0.1 & -0.1 & 0.3 & N.S \\
\hline MTLCL* & 0.0 & 0.1 & -0.3 & N.S & -0.3 & -0.1 & -0.6 & 0.0313 \\
\hline Total change in ER/IR & 3.0 & & & & 0.7 & & & \\
\hline
\end{tabular}

Significant $p$ values $<0.05$ are in bold

+12 knees; * 6 knees

STAR Tibial Axial Rotation Test

External/Internal Rotation

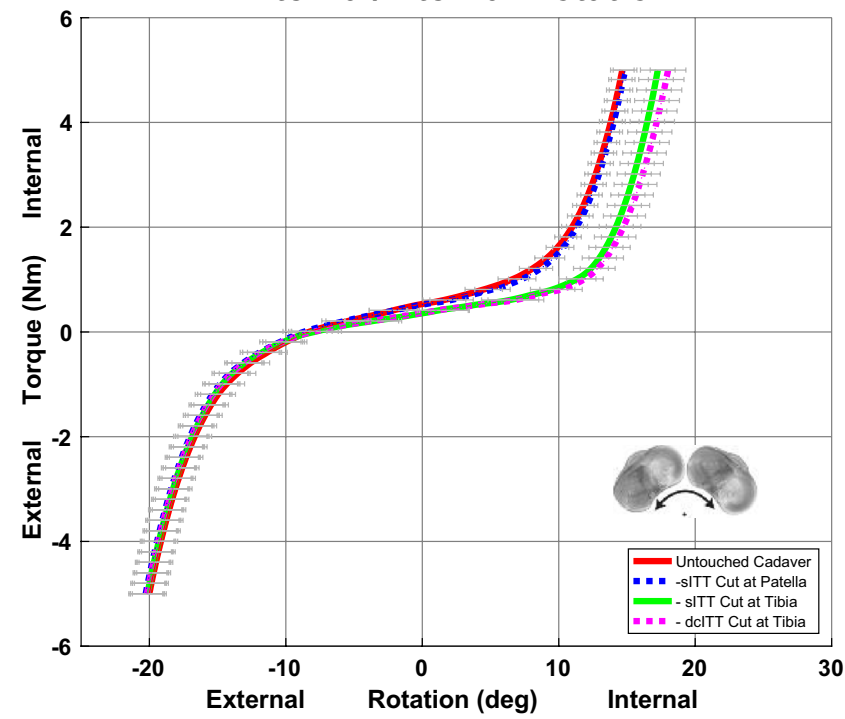

Adduction/Abduction Rotation

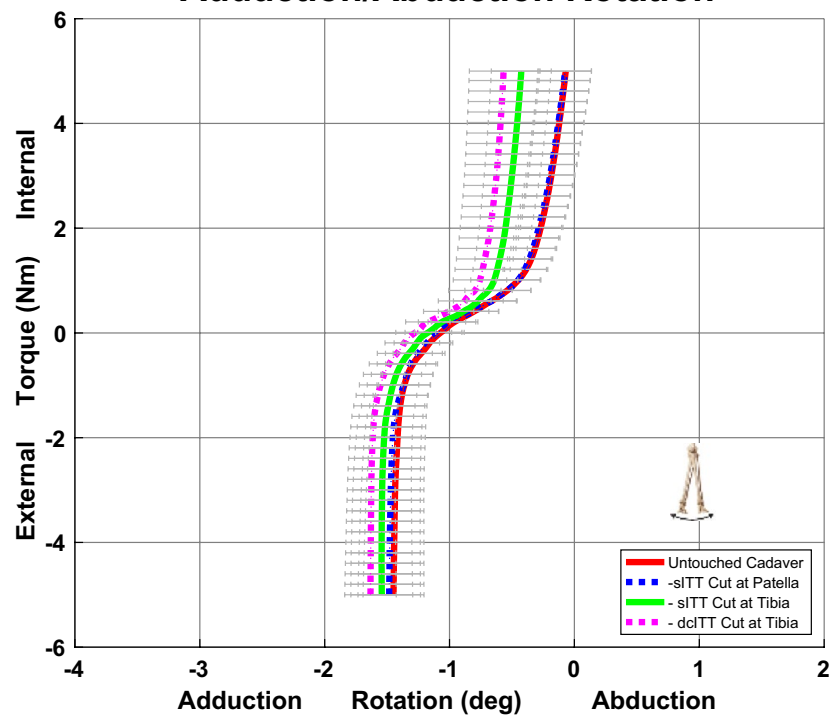

Fig. 2 Results of the tibial axial rotation test showing the primary motion of external/internal rotation (left) and the secondary motion of abduction/abduction (right)

rotation and anterior translation during the varus-valgus stress test caused by the sequential release of the ligaments. Importantly, the increase in adduction rotation during the varus-valgus stress test may be helpful in uniquely identifying an injury to these structures in the ACL intact knee.
Another important finding of this study was that release of the ALL, considered as the dcITT, had only a small impact on controlling knee motion. Furthermore, increases in motion caused by release of the dcITT mimicked those of the sITB making it clinically indistinguishable from each 


\section{STAR Anterior/Posterior Lachman Test}
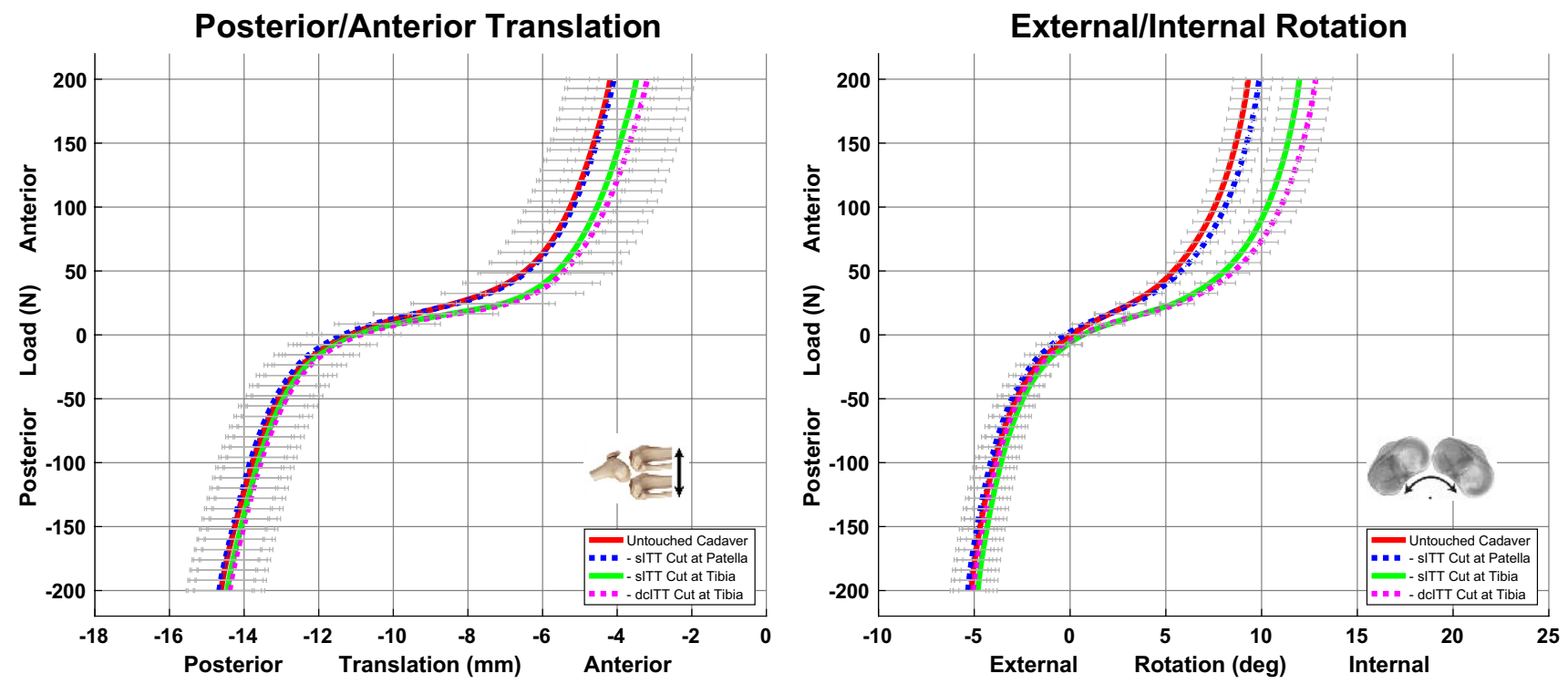

Fig. 3 Results of the anterior/posterior Lachman test with the primary motion of posterior/anterior translation (left) and the secondary motion of external/internal rotation (right)

\section{STAR Varus/Valgus Stress Test}
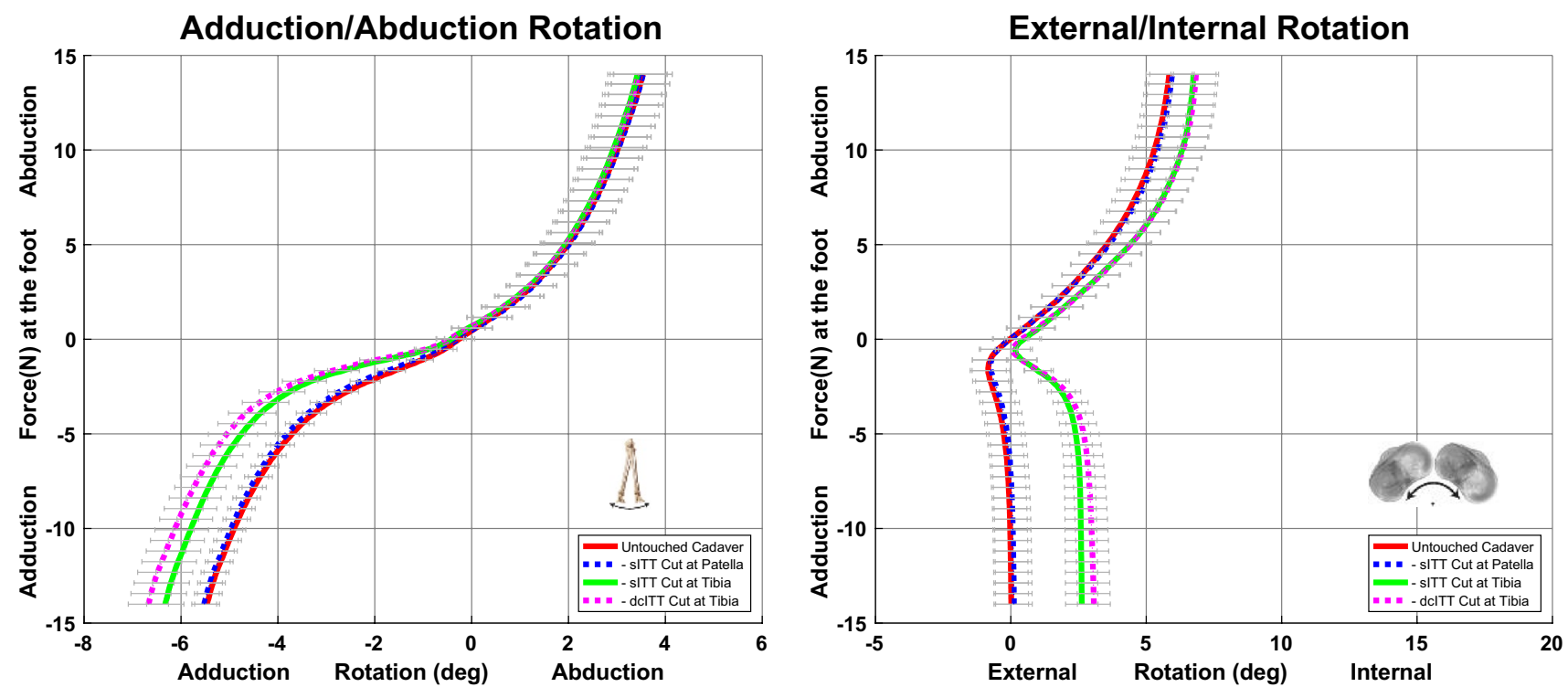

Fig. 4 Results of the varus-valgus stress test with the primary motion of adduction/abduction rotation and the secondary motion of externalinternal rotation

other. Sectioning of the 'other' defined ALL, the MTLCL, had little significant impact on controlling tibial motion with respect to the femur. Results of cutting the anterolateral capsule in the primary motions for each test as well as the most affected secondary motion were reported to provide the clinician with information to improve their clinical knee examination.
The findings from the current study are broadly in line with what is known about the role of the ITT in terms of rotational control. In his article, Glenn Terry combined findings at surgical exposure with findings using the clinical knee examination [22]. It was suggested that damage to the ITT occurred proximally with a focus on injury at the dcITT level. Furthermore, it was found that knees with 
dcITT damage had more adduction during the clinical knee examination, which was confirmed in the current study. Differentiating between an isolated ACL tear and an ACL with combined anterolateral capsule complex instability is possible through identification of the increased abduction rotation seen after injury to the anterolateral complex. Whether or not this is still valid in an ACL deficient knee will require further study. Gadikota et al., in a robotic study investigating the effect of increasing iliotibial band load, found that internal rotation was significantly reduced between $20^{\circ}$ and $30^{\circ}$ of knee flexion with an load of $50 \mathrm{~N}$, and from $15^{\circ}$ to $30^{\circ}$ with a load of $100 \mathrm{~N}$ [10]. Fairclough et al., in an anatomical study of the iliotibial band, suggested it consisted of, "a 'tendinous' part proximal to the lateral femoral epicondyle and a 'ligamentous' part between the epicondyle and Gerdy's tubercle" [9]. They suggested that this ligamentous portion, from Kaplan's fibers to Gerdy's tubercle, may function as an independent static restraint of internal tibial rotation. More recently, Kittl et al. reported the results of a robotic cadaveric study of the role of the sITT and dcITT in internal rotational control [15]. They found the superficial and deep layers of the ITT to be the main restraints to internal rotation and to a simulated pivot shift, with the ALL contributing little to stability. Other studies have suggested that the ALL, considered as the dcITT or the MTLCL, contribute to internal rotation control in varying degrees $[1,9,15,16]$. All three ligaments, sITT, dcITT and the MTLCL contribute to internal rotational control of the tibia with respect to the femur to some degree. Only the sITT and the dcITT appear to contribute to adduction control of the tibia with respect to the femur. Individual ligament contribution may be less important than the combined impact of injury to all three of the ligaments.

This study is subject to a number of limitations. This cadaveric study involved sequential release of multiple ligamentous structures and is subject to all issues related to cutting order. Furthermore, in vivo injury to the sITT and/ or dcITT likely occurs proximally [22], and thus, while our distal release is likely to have the same biomechanical effects, the injury location may be different. While we chose to completely release the anterolateral meniscotibial ligament to section the MTLCL, there may be retained function through the meniscofemoral ligament. In addition only six knees were tested for the MTLCL compared to 12 knees for the sITT or dcITT. All testing was performed at a single knee flexion angle of $30^{\circ}$. Parsons et al. demonstrated a wide variance in the contribution of the dcITT to internal rotation control between specimens at this flexion angle [16]. Our results may have been more consistent across all specimens at a higher or lower knee flexion angle. Due to the high test-retest consistency of the robotic testing device, very small magnitude changes in rotation and displacement may be highly statistically significant, even with a small number of cadaveric specimens. Care should be taken in interpreting the clinical significance of these small changes.

\section{Conclusion}

The presence of increased adduction during an automated knee examination provides unique information identifying the release of the sITT, dcITT and the MTLCL in this cadaveric study. While their sequential release caused similar pattern changes in the three components of the automated knee examination, the extent of change due to release of the MTLCL was markedly less than after release of the dcITT which was markedly less than after release of the sITT.

\section{Compliance with ethical standards}

Conflict of interest The authors declare that they have no conflict of interest.

Funding This study was funded by ERMI, Inc.

Ethics approval This article does not contain any studies with human participants or animals performed by any of the authors.

Informed consent For this type of study formal consent is not required.

Open Access This article is distributed under the terms of the Creative Commons Attribution 4.0 International License (http:// creativecommons.org/licenses/by/4.0/), which permits unrestricted use, distribution, and reproduction in any medium, provided you give appropriate credit to the original author(s) and the source, provide a link to the Creative Commons license, and indicate if changes were made.

\section{References}

1. Al Saiegh Y, Suero EM, Guenther D, Hawi N, Decker S, Krettek C, Citak M, Omar M (2015) Sectioning the anterolateral ligament did not increase tibiofemoral translation or rotation in an ACL-deficient cadaveric model. Knee Surg Sports Traumatol Arthrosc. doi:10.1007/s00167-015-3787-1

2. Bonanzinga T, Signorelli C, Grassi A, Lopomo N, Bragonzoni L, Zaffagnini S, Marcacci M (2016) Kinematics of ACL and anterolateral ligament. Part 1: Combined lesion. Knee Surg Sports Traumatol Arthrosc. doi:10.1007/s00167-016-4259-y

3. Branch TP, Stinton SK, Browne J, Lording T, deJarnette NK, Hutton WC (2016) A robotic system for measuring the relative motion between the femur and tibia. In: Musahl V, Karlsson J, Kuroda R, Zaffagnini S (eds) Rotatory knee instability: an evidence based approach. Springer, New York ISBN: 978-3-319-32069-4 
4. Branch TP, Stinton SK, Siebold R, Freedberg HI, Jacobs CA, Hutton WC (2015) Assessment of knee laxity using a robotic testing device: a comparison to the manual clinical knee examination. Knee Surg Sports Traumatol Arthrosc. doi:10.1007/ s00167-015-3935-7

5. Branch T, Stinton S, Sternberg M, Hutton W, Lavoie F, Guier C, Neyret P (2015) Robotic axial lower leg testing: repeatability and reproducibility. Knee Surg Sports Traumatol Arthrosc 23:2892-2899

6. Caterine S, Litchfield R, Johnson M, Chronik B, Getgood A (2015) A cadaveric study of the anterolateral ligament: re-introducing the lateral capsular ligament. Knee Surg Sports Traumatol Arthrosc 23:3186-3195

7. Claes S, Vereecke E, Maes M, Victor J, Verdonk P, Bellemans J (2013) Anatomy of the anterolateral ligament of the knee. J Anat 223:321-328

8. Dodds AL, Halewood C, Gupte CM, Williams A, Amis AA (2014) The anterolateral ligament: Anatomy, length changes and association with the Segond fracture. Bone Joint J 96-B:325-331

9. Fairclough J, Hayashi K, Toumi H, Lyons K, Bydder G, Phillips N, Best TM, Benjamin M (2006) The functional anatomy of the iliotibial band during flexion and extension of the knee: implications for understanding iliotibial band syndrome. J Anat 208:309-316

10. Gadikota HR, Kikuta S, Qi W, Nolan D, Gill TJ, Li G (2013) Effect of increased iliotibial band load on tibiofemoral kinematics and force distributions: a direct measurement in cadaveric knees. J Orthop Sports Phys Ther 43:478-485

11. Guenther D, Griffith C, Lesniak B, Lopomo N, Grassi A, Zaffagnini S, Fu FH, Musahl V (2015) Anterolateral rotatory instability of the knee. Knee Surg Sports Traumatol Arthrosc 23:2909-2917

12. Helito CP, Demange MK, Bonadio MB, Tirico LE, Gobbi RG, Pecora JR, Camanho GL (2013) Anatomy and histology of the knee anterolateral ligament. Orthop J Sports Med 1(7):2325967113513546

13. Helito CP, Demange MK, Bonadio MB, Tirico LE, Gobbi RG, Pecora JR, Camanho GL (2014) Radiographic landmarks for locating the femoral origin and tibial insertion of the knee anterolateral ligament. Am J Sports Med 42:2356-2362

14. Kaplan EB (1957) Surgical approach to the lateral (peroneal) side of the knee joint. Surg Gynecol Obstet 104:346-356
15. Kittl C, El-Daou H, Athwal KK, Gupte CM, Weiler A, Williams A, Amis AA (2016) The role of the anterolateral structures and the acl in controlling laxity of the intact and acl-deficient knee. Am J Sports Med 44:345-354

16. Parsons EM, Gee AO, Spiekerman C, Cavanagh PR (2015) The biomechanical function of the anterolateral ligament of the knee. Am J Sports Med 43:669-674

17. Pomajzl R, Maerz T, Shams C, Guettler J, Bicos J (2015) A review of the anterolateral ligament of the knee: current knowledge regarding its incidence, anatomy, biomechanics, and surgical dissection. Arthroscopy 31:583-591

18. Rasmussen MT, nitri M, Williams BT, Moulton SG, Serra Cruz R, Dornan GJ, Goldsmith MT, LaPrade RF (2016) An in vitro robotic assessment of the anterolateral ligament, part 1: Secondary role of the anterolateral ligament in the setting of an anterior cruciate ligament injury. Am J Sports Med 44:585-592

19. Rezansoff AJ, Caterine S, Spencer L, Tran MN, Litchfield RB, Getgood AM (2015) Radiographic landmarks for surgical reconstruction of the anterolateral ligament of the knee. Knee Surg Sports Traumatol Arthrosc 23:3196-3201

20. Siebold R, Takada T, Feil S, Dietrich C, Stinton SK, Branch TP (2016) Anatomical "C Shape" double bundle versus single bundle anterior cruciate ligament reconstruction in pre-adolescent children with open growth plates. Knee Surg Sports Traumatol Arthrosc 24:796-806

21. Stinton SK, Siebold R, Freedberg H, Jacobs C, Branch TP (2016) The use of a robotic tibial rotation device and an electromagnetic tracking system to accurately reproduce the clinical dial test. Knee Surg Sports Traumatol Arthrosc 24:815-822

22. Terry GC, Norwood LA, Hughston JC, Caldwell KM (1993) How iliotibial tract injuries of the knee combine with acute anterior cruciate ligament tears to influence abnormal anterior tibial displacement. Am J Sports Med 21:55-60

23. Thein R, Boorman-Padgett J, Stone K, Wickiewicz TL, Imhauser CW, Pearle AD (2016) Biomechanical assessment of the anterolateral ligament of the knee. J Bone Joint Surg Am 98:937-943

24. Vincent J-P, Magnussen RA, Gezmez F, Uguen A, Jacobi M, Weppe F, Al-Saati MF, Lustig S, Demey G, Servien E, Neyret $P$ (2011) The anterolateral ligament of the human knee: an anatomic and histologic study. Knee Surg Sports Traumatol Arthrosc 20:147-152 